\title{
Application of Regional Financial Security Index in China
}

\author{
Guomei $\mathrm{Fu}^{1, \mathrm{a}}$, Xiaohui $\mathrm{Hu}^{1, \mathrm{~b},{ }^{*}}$ Fuchang $\mathrm{Li}^{1, \mathrm{c}}$
}

${ }^{1}$ School of Economics \& Management, Yunnan Normal University, Juxian Street, Kunming, China

1a1414782301@qq.com ,1b75042344@qq.com, ${ }^{1 c} 24695192 @ q q . c o m$

*corresponding author

Keywords: Regional financial Security index

\begin{abstract}
Under the new normal of economic development, the driving force of China's economic development has undergone a profound transformation, and we must pay attention to prevent the occurrence of regional financial risks. Therefore, the application of regional financial security identification system is very important to the healthy operation of China's economy.
\end{abstract}

\section{Introduction}

Financial security is an important part of national security, and it is also an important guarantee for the healthy and China's economy. Moreover, the status of financial security in national economic security is becoming more and more prominent. As the degree of financial liberalization continues to strengthen, the requirements for the financial system to resist risks continue to improve. The differences in the degree of financial openness in China's eastern and western regions are obvious, so the requirements for the ability to resist financial risks are also different. Therefore, when applying the application of regional financial security index, it is necessary to investigate the financial risk situation according to the development characteristics of each region.

Based on the current situation of regional financial security in China, this paper provides a feasible reference index for the accurate measurement of regional financial security in China, and provides a reliable guarantee for the risk prevention of financial supervision departments in China.

\section{Overview of regional financial security index}

\subsection{Definition of regional financial risk}

Regional financial risk refers to the possibility of loss caused by individual or partial financial institutions or certain financial activities in a certain region. It is different from micro financial risk and macro financial risk, it is a kind of medium financial risk which can spread in the region and cause regional financial turbulence. It is mainly manifested as the large-scale bankruptcy of regional financial institutions, the serious loss of residents' financial assets and the disorder of regional financial order and so on.

\subsection{Characteristics of regional financial risk}

Firstly, regional financial risk is a regional concept. Therefore, it is wrong to think that the risks caused by local financial institutions are regional financial risks and the risks caused by national financial institutions are not regional financial risks. Secondly, local financial institutions and illegal social financial activities are most likely to trigger regional financial risks. Local financial institutions, such as local Banks, local financial companies and investment companies are lack of funds and have poor ability to resist risks, which may easily lead to financial risks. Thirdly, regional financial risks have quantitative limits. If the financial risk of a single financial institution or financial activity in the region does not exceed its own scope, it is only an individual financial risk. Financial risks are formed when multiple financial institutions in the region take place at the same time, or when individual financial risks are improperly handled or spread to other regional financial institutions. 


\subsection{Cause analysis of regional financial risk}

Firstly, macro factors include macro-financial policy, degree of financial openness and soundness of financial supervision system. Different regions have different levels of financial industry growth. Regions with a high level of financial industry growth can rapidly adjust financial activities to achieve expected policy effects. However, in regions with low growth level of financial industry, financial instruments and financial organizations are relatively single. In the face of adjustment of financial activities, it is basically impossible to eliminate the impact of policy adjustment. Therefore, financial risks tend to form and accumulate. Secondly, the medium factor mainly refers to the local government's intervention in financial activities. Local government intervention in financial activities driven by interests will reduce the use efficiency of financial resources. Moreover, government intervention will increase the operational risks of the financial industry. Thirdly, micro factors mainly include internal control mechanism, financial market soundness and human resource conditions of the financial industry. The establishment of modern financial property system and operation mechanism can reduce the probability of micro-financial risks and prevent the accumulation and spread of micro-financial risks.

\section{Application of regional financial security index}

Regional financial security index is an objective reflection of regional financial operation state. This paper selects regional financial industry index, regional fixed asset investment index, regional consumption index, regional industrial development index, regional macroeconomic growth index and regional external environment index to form the regional financial security index system. Among them, the index of regional financial industry index is to measure the development status of the financial industry in the region. The healthy development of the financial industry means a higher degree of regional financial security. Regional fixed asset investment index can reflect the overall investment status of regional fixed assets and real estate, which fully considers the influence of fixed asset investment on the stability of regional economy. The regional consumption index measures the consumption level in the region, reflects the level of economic development, and then affects the regional financial security. Regional industrial development index can measure the development status of industrial enterprises in the region, which plays an important role in regional financial security. The regional macroeconomic growth index reflects the regional macroeconomic operation; Regional external environment index measures the operation of macro-economic environment outside the region. A good external economic environment plays an important supporting role for the healthy development of various industries in the region, and thus affects the regional financial security.

In the first half of 2007, China's financial security situation showed a positive trend, mainly because the reform of commercial Banks showed a relatively significant effect. From the second half of 2007, the outbreak of the subprime mortgage crisis in the United States led to great fluctuations in China's foreign trade, and the operation of the capital market was also unstable. As a result, China's economy showed a downward trend in 2008, which had a certain impact on China's economic operation. After that, China implemented a number of positive economic policies to expand domestic demand, which has played a certain role in guaranteeing the stable development of China's economy. In 2009, China's macroeconomic situation has been improved. In 2010, China's GDP growth rate reached more than $10 \%$. The operating status of Banks and other financial institutions has gradually improved, and the financial security index has significantly increased. From 2011 to 2015, the rapid development of Internet finance deepened financial innovation and increased the possibility of financial insecurity. Moreover, from 2012 to 2013, a serious debt crisis broke out in Europe, increasing the external risks faced by China's financial market. However, China's central and local governments made joint efforts to effectively control the risk, making this stage of financial security shows a steady trend of health. In 2016, China's macroeconomic performance has been relatively stable. In addition, from 2007 to 2010, the financial security index in the eastern, central and western regions of China showed an overall trend of "N". From 2011 to 
2014, the overall performance was relatively stable, and from 2015 to 2017, it showed a "V" shape.

\section{Conclusion}

From the perspective of the economic operation of the three major economic regions in the east, the west and the east in previous years, the subprime crisis broke out in 2008, and the gross product of the three economic regions, commercial housing sales, etc. all showed a certain degree of decline compared to 2007. Because the economic structure, geographical location and development degree of the three regions are different, the impact of the subprime crisis on the financial security index of the three regions shows a certain time lag. The central and western regions continued to steadily advance the strategy of transformation and development, actively adapted to the new trend of national economic development, and maintained a sound overall investment and consumption environment. With the in-depth implementation of supply-side structural reform, "One Belt And One Road", poverty alleviation strategy and the introduction of relevant national laws and policies, the importance of financial security and stability has been raised to a new height.In conclusion, the application of regional financial security index plays an important role in the stability of China's financial market.

\section{Policy suggestions}

Firstly, we should improve the assessment system for regional financial risks, focusing on the monitoring and give full play to the role of early risk assessment in preventing regional financial risks. Make full use of the data resources at the micro level of each region, effectively identify the financial security status, and timely issue early warning signals. Secondly, it is important to strengthen the coordination among regional financial supervision, and form a strong force to jointly resist financial risks. At the same time, we need to strengthen oversight over the operation of the real economy, especially in key industries and enterprises, to prevent contagion of financial risks. Thirdly, Shadow banking is the main factor of liquidity risk in China, so it is necessary to strengthen cross-border financial supervision of shadow banking and Internet, and promote the standardized development of emerging financial formats. In addition, China's current industry development trend has posed a great challenge to the development model of financial regulation, which needs to be adjusted. Relevant departments should make full use of big data technology and network technology, and with high-level science and technology as the support, establish an efficient regulatory information platform. If a certain industry crisis, can be timely isolated risk sources, cut off the transmission channels, effectively control financial risk.

\section{Acknowledgments}

I am very grateful to the anonymous editors and the other authors. This research is supported by the national natural science foundation of China $(71562036,71362028)$;Yunnan philosophy and social science education science planning project (AD18012);Education program of industry-university cooperation of the ministry of education (201802098054);Scientific research fund project of yunnan provincial department of education (2018JS140).

\section{Reference}

[1] Illing M,LiuY.Measuring Financial Stress in A Developed Country: An Application to Canada [J].Journal of Financial Stability,2006,2 (3):243-265.

[2] Edison J W.Equity and Bond Market Signals as Leading Indicators of Bank Fragility [J].European Central Bank Working Paper,2002,10 (6):35-48.

[3] Hakkio C S, Keeton W R. Financial Stress: What Is It, How Can It Be Measured, and Why Does It Matter? [J].Economic R eview,2009,94(2): 5-50. 
[4] Brave S A, Butters R A Gathering Insights on the Forest from the Trees: A New Metric for Financial Conditions [J].Social Science Electronic Publishing, 2010,7 (10):1-36.

[5] Zihui Yang, Yutian Chen, Rukai Xie. Systematic financial risk measurement and cross-sector risk spillover effect of financial institutions in China [J]. Journal of financial research, 2018(10).

[6] Bin Zhong, Nian liu, Shunrong Bi. Discussion on the theory and practice of regional financial risk early warning system [J]. Financial research, 2002 (7) : 105-111. 